\title{
ASSESSING MORAL REASONING, COGNITIVE DISTORTIONS AND DRIVING STYLE IN THE CONTEXT OF POST-LICENSE YOUNG DRIVER COACHING
}

\author{
Erik Roelofs ${ }^{1}$, Pierro Hirsch ${ }^{2}$ \\ ${ }^{1}$ Cito, Arnhem, The Netherlands, ${ }^{2}$ Virage Simulation, Montreal, Canada \\ Email: Erik.Roelofs@cito.nl
}

\begin{abstract}
Summary: As part of the Dutch post-license young driver coaching program, Drive Xperience (DX), the level of moral reasoning was explored in relation to self-reported violating driving behaviors. Drawing from literature in the field of juvenile crime, three online assessments were developed to measure: a) social driving behavior; b) moral justification for rule compliance, and: c) cognitive distortions in relation to socially undesirable driving behavior. The assessments were administered between fall 2014 and fall 2016 to 1660 participants in the DXprogram. The results show that immature levels of moral reasoning and prevalence of cognitive distortions are strongly associated with self-reported speed choice, space competition and traffic law violations.
\end{abstract}

\section{INTRODUCTION}

To counteract the high crash risk of young novice drivers in the first months of their driving career, several countries have introduced post-license training programs that address factors that Gregersen et al. have identified as contributing to crash risk (Gregersen \& Bjurulf, 1996). Higher order skills are associated with lower crash risk. Training effects have been found for programs that focus on higher order skills, including situational awareness and self-evaluation (Isler, Starkey, \& Sheppard, 2011, Beanland, Goode, Salmon, \& Lenné, 2013). More recently, interpersonal skills related to road safety, such as avoiding rides with drunk drivers and resisting peer pressure to drive unsafely, are addressed in training to improve resilience (King et al., 2008). Studies on juvenile delinquency have shown that an immature level of moral reasoning is a strong predictor for delinquent behaviors (Stams, Brugman, Deković, \& van Rosmalen, 2006). Moral reasoning is being considered as a social-emotional skill that could potentially be addressed in the Dutch post-license young driver coaching program, Drive Xperience. In the current study, we explored whether moral reasoning in traffic contexts is in fact related to highcrash risk driving behavior and traffic violations.

\section{Delay in Moral reasoning level and prevalence of self- serving cognitive distortions}

People use moral reasoning to justify about what they consider to be right and wrong in a personal situation of moral conflict. For example, what should a person do when he has just paid for groceries, left the shop, and then discovered he was given $\$ 5$ too much in change? Keep it or return to the store to give it back? Gibbs (2003) distinguishes four typical stages of development in moral reasoning. In stage 1, moral justifications are based upon authority and are rule based, or related to punitive consequences of rule violations. In stage 2 , moral justifications are based upon an understanding arising from social interactions. Decisions to help others may be justified by expectations of reciprocal help in the future. In stage 3, moral justifications are characterized by further decentration, the ability to consider multiple aspects of a situation, and are based upon 
a pro social understanding of emotional states (e.g. empathy), care and good conduct. The most mature stage, stage 4 , is characterized by the development of an understanding of the complex social structures in which we live. Justifications are also based upon rights, values, social justice and responsibility.

Gregg, Gibbs, and Basinger (1994) found that the area of greatest delay in moral judgment concerned the reasons for obeying the law. They used the socio-moral reflection measure, consisting of eleven questions related to five abstract moral value areas: contract and truth; affiliation; life; property and law, and legal justice. Subjects rated the importance of each value and wrote a short justification for their rating. Experts then scored the justifications in terms of the stages of moral development. Results showed that non delinquents more frequently gave stage 3 justifications, e.g., people's mutual expectations of adherence to the law, the selfishness of law breaking, and the resulting chaos, insecurity, or loss of trust in the world. In contrast, the delinquents' justifications for their ratings generally appealed to stages 1 and 2 concerns about the risk of getting caught and going to jail.

It is important to note that developmental delays in moral judgment do not necessarily lead to antisocial behavior. Empirical research has shown that cognitive distortions also appear to mediate the relation between socio-moral development and antisocial behavior (Barriga, Morrison, Liau, \& Gibbs, 2001). Cognitive distortions are defined as inaccurate or rationalizing attitudes, thoughts, or beliefs concerning one's own or other's social behavior (Gibbs, 2003). Cognitive distortions help protect the self from blame or a negative self-concept and tend to disinhibit antisocial behavior. Gibbs distinguishes four types of cognitive distortions. 1) Selfcentered reasoning: attributes predominance to one's own views, expectations, needs, rights, immediate feelings, and desires to the exclusion of the legitimate views or needs of others. 2) Blaming others: misattributes responsibility to outside sources, especially other persons, group, or unusual events. 3) Minimizing or mislabeling: depicts antisocial behavior as harmless, acceptable or admirable, or belittles or dehumanizes others. 4) Assuming the worst: gratuitously attributes hostile intentions to others or assumes the inevitability of worst-case scenarios for social situations, or assumes that improvements in one's own or others' behavior is impossible.

\section{Moral reasoning as a basis for socio-moral reflection in young driver coaching}

Since 2003, the Dutch post-license young driver coaching program, DriveXperience (DX), is used to counteract high crash risk by addressing higher order skills such as situation awareness and resistance to peer pressure to drink and drive. As part of the program participants do selfassessments intended to elicit self-reflection. Recently, the moral component of driving competence has been considered as an addition to the program based on the promising results that show that young delinquents can be trained to attain more advanced levels of moral reasoning and pro-social behavior (Leeman, Gibbs, \& Fuller, 1993; Van Stam et al., 2014). The potential effectiveness of adding a section on moral reasoning in traffic situations to the program was tested in the current study. Three additional online self-assessments were developed to investigate reported levels of moral reasoning, and relationships between moral reasoning, selfreported driving behavior and driving violations. The self-assessments were designed to address two research questions. 1) Which levels of moral reasoning in traffic situations are used by 
young drivers who take part in the DX-program? 2) To which extent is moral reasoning related to self-reported driving behavior, including speed choice, rule compliance and traffic violations?

\section{METHOD}

\section{Online assessments and questionnaires}

Three online assessments were developed. First, the 'Social Driving' (SD) assessment consists of 18 traffic situations in which there is a conflict of space between the driver and other road users. For instance, in one situation, both the driver and another road user from the opposite direction approach a narrow point on the road. In responding to the question "what would you do in this situation", the driver is given three options and asked to distribute 100 points over these options, e.g. 25 points for option one, 25 point for option two and 50 points for option three. The first option is to compete for the space with the other road user, e.g., "I accelerate to arrive at the point first". The second option is to allot the space to the other road user, e.g. "I brake to let the other car go first". The third option is to wait and see what happens first, e.g. "I reduce speed to see whether the other driver is going to stop". Only scores on the first two options are counted across all 18 traffic situations to form scales for 'space competing driving behavior' and 'space allotting driving behavior' respectively, which can vary between 0 and 100 . The third "wait and see" option was not included in a scale. Second, the 'motives for rule compliance' (MRC) assessment, consists of 15 photos of traffic violations, that occur frequently according to Dutch police statistics. The respondent is asked how many times out of ten he would commit the pictured traffic violation. On the follow-up question, why he would comply to the traffic rule, the driver is asked to distribute 100 points over four options, each representing a different moral reasoning level: 1 . Preventing fines or being stopped by the police; 2 . Preventing uncomfortable or unsafe situations for oneself; 3. Preventing uncomfortable or unsafe situations for other road users; 4. Preventing unsafe situations or maintaining the traffic flow. Third, the Cognitive Distortions in Driving (CDD) test measures the degree to which drivers make self-serving cognitive distortions regarding socially undesirable driving behavior. This questionnaire consists of 43 items and was derived from the original How I Think Questionnaire (Gibbs, Barriga, and Potter, 2001). An example of an item for "self-centered reasoning" is: "When I have to arrive at a meeting on time, I allow myself to drive faster than the speed limit." An example of "blaming others" is: "I tailgate other vehicles on the highway because they do not move through the traffic quickly enough." An example of minimizing/mislabeling is: "If I return to my car quickly, it is not a big deal to park in a restricted area." An example of "assuming the worst" is: "When I want to merge in traffic, other road users do not voluntarily let me in". To prevent response bias, seven items with a positively worded neutral statement were added. For example: "People should feel at ease when they are in traffic". For all items, the driver responds on a six-point Likert scale, ranging from 'disagree strongly' to 'agree strongly'. Finally, as part of the CDD test, additional questions were included about preferred driving speeds on $50 \mathrm{~km} / \mathrm{h}, 80 \mathrm{~km} / \mathrm{h}, 120 \mathrm{~km} / \mathrm{h}$ roads under a) quiet traffic conditions, b) busy traffic conditions, and; c) in rainy weather. In addition, respondents were asked how many fines they had received since licensing for each of twelve types of traffic violations (e.g. not wearing seat belts, speeding, making hand-held phone calls). 


\section{Subjects}

The study population consisted of 2280 recently licensed drivers (mean age: 19.8 years, mean license age: 18.7 years, 52.3 per cent male) from different educational backgrounds enrolled in the DX-program from fall 2014 to fall 2016. They came from 62 Dutch municipalities and participated on a voluntary basis after they had been invited by their respective mayors. The program was financed by Regional Agencies for Traffic Safety in the provinces of Gelderland, South-Holland and Limburg. On average, 75 per cent of the participants enrolled in the DXprogram responded to the assessments. The most frequently reported reason for non-response was lack of time. All participants took the CDD test. To reduce the testing load, the MRC and the SD tests were administered alternately, resulting in lower n's for these assessments.

\section{RESULTS}

Table 1 shows the mean scores for the SD and MRC assessments. The subscale 'Space allotting driving' has moderate internal consistency (alpha coefficient: .65). On average, in 53.3 per cent of the situations drivers choose to allot space to the other road user. The subscale 'space competing driving' of the SD test has acceptable internal consistency (alpha coefficient: .73). Drivers choose for space competing driving in 16.7 per cent of the situations. Results of the MRC test show that participants report motives for all four levels of moral reasoning. At the same time, there is a large range of scores within each motive. All subscales have alpha coefficients above .70, which indicates adequate internal consistency.

Table 1. Percentage of situations in which drivers choose pro-social or space competing driving and specific motives for complying with traffic rules

\begin{tabular}{|c|c|c|c|c|}
\hline & Mean & $S D$ & Min & Max \\
\hline \multicolumn{5}{|l|}{ Social Driving (SD; $n=839$; all scales range from 0 to100)* } \\
\hline Space allotting driving behavior ( 18 items, $\alpha=.65$ ) & 53.3 & 10.0 & 22.8 & 95.4 \\
\hline Space competing driving at the expense of others (18 items, $\alpha=.73$ ) & 16.7 & 9.5 & 0.0 & 56.1 \\
\hline \multicolumn{5}{|l|}{ Motives for Rule Compliance (MRC; $n=921$; scales theoretically range from 0 to100) } \\
\hline Motive 1 . Prevent fines or being stopped by the police ( 15 items, $\alpha=.85$ ) & 19.1 & 14.2 & 0 & 86.5 \\
\hline Motive 2. Prevent uncomfortable/unsafe situations for oneself ( 15 items, $\alpha=.77$ ) & 28.3 & 9.2 & 0 & 67.3 \\
\hline Motive 3. Prevent uncomfortable/unsafe situations for other road users ( 15 items, $\alpha=.77$ ) & 26.9 & 8.5 & 0 & 83.3 \\
\hline Motive 4. Prevent unsafety or blocking of traffic flow ( 15 items, $\alpha=.86$ ) & 25.6 & 11.3 & 0 & 84.0 \\
\hline
\end{tabular}

Note * The option 'wait and see' was not included in a scale; hence scale means for two subscales do not add up to 100.

Table 2. Cognitive distortions in moral reasoning about socially undesirable driving behavior

\begin{tabular}{|c|c|c|c|c|c|c|c|c|}
\hline \multirow[b]{2}{*}{ Cognitive Distortions in Driving (CDD; $n=1660)$} & \multicolumn{4}{|c|}{ Scale statistics } & \multicolumn{4}{|c|}{$\begin{array}{c}\text { Category statistics: prevalence } \\
\text { of cognitive distortion* }\end{array}$} \\
\hline & Mean & SD & $\min$ & $\max$ & $\begin{array}{c}\text { very } \\
\text { unlikely }\end{array}$ & unlikely & likely & $\begin{array}{l}\text { very } \\
\text { likely }\end{array}$ \\
\hline 1: Self-centered reasoning ( 9 items, $\alpha=.70)^{1}$ & 24.5 & 12.4 & 0.0 & 73.3 & $45 \%$ & $40 \%$ & $11 \%$ & $4 \%$ \\
\hline 2: Blaming others $(10 \text { items, } \alpha=.80)^{2}$ & 33.5 & 15.1 & 0.0 & 88.0 & $44 \%$ & $33 \%$ & $17 \%$ & $5 \%$ \\
\hline 3: Minimizing/mislabeling ( 9 items, $\alpha=.73)^{1}$ & 22.8 & 13.2 & 0.0 & 91.1 & $48 \%$ & $31 \%$ & $16 \%$ & $4 \%$ \\
\hline 4: Assuming the worst $(10 \text { items, } \alpha=.68)^{3}$ & 29.5 & 13.8 & 0.0 & 87.5 & $41 \%$ & $36 \%$ & $18 \%$ & $5 \%$ \\
\hline Overall cognitive distortions ( 38 items, $\alpha=.91)^{1}$ & 26.5 & 11.4 & 0.0 & 74.2 & $30 \%$ & $49 \%$ & $17 \%$ & $4 \%$ \\
\hline
\end{tabular}

Note. ${ }^{* 1,2,3}$ Cut-off scores for prevalence categories: ${ }^{1}: 0-20 ; 20-35: 35-47: 47-100 ;{ }^{2}: 0-30: 30-46 ; 46-60: 60-100$;

3: 0-30: 30-46: 46-60; 60-100

Table 2 shows the scores of DX-participants on Cognitive Distortions in Driving, expressed on a scale from 0 to 100 , which result from a linear transformation of the sum scores for the original response categories (0-5). The average scores for all cognitive distortions subscales are relatively 
low, ranging from 22.8 for mislabeling socially undesirable driving behavior to 33.5 for blaming others for one's own socially undesirable driving behavior. All subscales have alpha coefficients above .70, which indicates adequate internal consistency. Results from paired $t$-tests show that, compared to the other motives, blaming others occurs more frequently than the other types of distortions. The $t$-vales for the comparisons amount to $-32,54$ (Motive 2 vs. motive $1, d f=1559$, $p=.000$ ), 37,17 ( 2 vs. $3, d f=1559, p=.000)$, and 14.16 ( 2 vs. $4 ; d f=1559, p=.000$ ) respectively. After applying provisional cut-off scores for determining the prevalence of cognitive distortions, based on the original HIT cut-off scores by Gibbs et al. (2001), it can be seen in Table 2 that, in general, 21 per cent of the participants used cognitive distortions. Similar percentages of participants used the cognitive distortions of blaming others, mislabeling and assuming the worst. A smaller percentage of the DX-participants used self-centered reasoning.

Table 3 presents the results of three stepwise regression analyses in which self-reported driving behaviors were treated as dependent variables. In a stepwise procedure, the associations between these behaviors and three blocks of variables were tested, specifically, driver background characteristics; moral reasoning, and driving behavior. Beta-coefficients, $t$-values and the probabilities ( $p$-values) for $b e t a=0$ are also reported. The adjusted $R^{2}$-values, which can be interpreted as proportions of explained variance, are shown in the bottom row of the table. The first analysis focused on space-competing behavior and found two statistically significant associations. One, that the mature, moral-level motive, preventing unsafety or blocking of traffic flow, is negatively associated with space competing driving $(\beta=-.11)$. Two, that making cognitive distortions is positively associated with space competing driving $(\beta=.42)$. The total variance explained for the whole model is 21 per cent $\left(R^{2}=.21, F=95.8 .1, d f=3,732, p=.000\right)$.

Table 3. Results of stepwise regression analyses with driving behavior as dependent variables

\begin{tabular}{|c|c|c|c|c|c|c|c|c|c|}
\hline \multirow[b]{3}{*}{ Predictor variables } & \multicolumn{9}{|c|}{ Dependent variables regarding driving behavior } \\
\hline & \multicolumn{3}{|c|}{$\begin{array}{c}\text { Space } \\
\text { competing driving } \\
(n=395)\end{array}$} & \multicolumn{3}{|c|}{$\begin{array}{l}\text { Reported driving speed } * \\
\qquad(\mathrm{n}=735)\end{array}$} & \multicolumn{3}{|c|}{$\begin{array}{c}\text { Degree of violating driving } \\
\text { behavior* } \\
(n=395)\end{array}$} \\
\hline & $\beta$ & $t$ & $p$ & $\beta$ & $t$ & $p$ & $\beta$ & $t$ & $p$ \\
\hline \multicolumn{10}{|l|}{ Driver background characteristics } \\
\hline Gender $($ female $=0 ;$ male $=1)$ & $\mathrm{NE}$ & - & - & .17 & 5.2 & .000 & .13 & 3.2 & .002 \\
\hline Highest attained level of education $(1=; 2=3=$ & $\mathrm{NE}$ & - & - & - & - & - & - & - & - \\
\hline Age (range $17-30$ years) & $\mathrm{NE}$ & - & - & - & - & - & - & - & - \\
\hline Kilometers driven per year & $\mathrm{NE}$ & - & - & - & - & - & - & - & - \\
\hline Years of experience on moped & $\mathrm{NE}$ & - & - & - & - & - & NE & - & - \\
\hline \multicolumn{10}{|l|}{ Moral reasoning } \\
\hline Prevention of fines as motive for rule compliance & $\mathrm{NE}$ & - & - & $\mathrm{NE}$ & - & - & .18 & & .000 \\
\hline $\begin{array}{l}\text { Prevent unsafety or blocking of traffic flow as } \\
\text { motive for rule compliance }\end{array}$ & -.11 & -2.3 & .020 & $\mathrm{NE}$ & - & - & $\mathrm{NE}$ & - & - \\
\hline Cognitive distortions & .42 & 9.1 & .000 & .42 & 11.7 & .000 & .18 & 3.7 & .000 \\
\hline \multicolumn{10}{|l|}{ Driving behavior } \\
\hline Space competing driving & $\mathrm{NE}$ & - & - & .10 & 3.0 & .003 & .10 & 2.4 & .018 \\
\hline Reported driving speed (on various roads) & $\mathrm{NE}$ & - & - & $\mathrm{NE}$ & - & - & .36 & 7.9 & .000 \\
\hline Adjusted $R^{2}$ & .21 & & & .28 & & & .46 & & \\
\hline
\end{tabular}

Note: $\mathrm{NE}=$ variable not in the equation, after stepwise regression analysis; ${ }^{*}$ Total score for 9 items (Likert type with a 1-7 scale, representing various pre-set speed levels, $\alpha=.90) ; * *$ Total score for 15 items (Likert type with a $0-10$ scale, $\alpha=.82$ ).

The second analysis focused on self-reported driving speed and found that cognitive distortions $(\beta=.42)$ and space competing driving $(\beta=.10)$ are associated with higher speeds. Among the driver background variables, only gender was significant with men self reporting to drive faster than women $(\beta=.17)$. The percentage of variance explained in this regression model is 28 
$\left(R^{2}=.28, F=52.1, d f=2,393, p=.000\right)$. In the third analysis that focused on self-reported driving violations, the degree to which participants use prevention of fines as a motive for rule compliance is positively related to the degree of self-reported violating behavior $(\beta=18)$. Driving violation behavior is also associated with cognitive distortions $(\beta=.18)$, space-competing driving $(\beta=.10)$, and higher driving speeds on various roads $(\beta=.36)$. In addition, men report committing more driving violations than women $(\beta=.13)$. The proportion of variance explained by this model is 46 per cent $\left(R^{2}=.46, F=67.6, d f=5,390, p=.000\right)$.

Table 4 shows the results of a multiple regression analysis with the number of reported fines as dependent variable. The variance explained for the final model is 7 per cent $\left(R^{2}=.07, F=19.1\right.$, $d f=3,696, p=.000)$. After accounting for the degree of violating behavior $(\beta=.19)$, moral reasoning variables do not contribute in explained variance. In addition, mileage (kilometers driven per year) is positively related to the number of fines $(\beta=.13)$. Finally, it appears that higher educational levels are associated with fewer traffic fines $(\beta=-.09)$.

Table 4. Results of a stepwise regression analysis with reported number of fines as a dependent variable*

\begin{tabular}{|c|c|c|c|}
\hline \multirow[b]{2}{*}{ Predictor variables } & \multicolumn{3}{|c|}{ Number of fines $(n=699)$} \\
\hline & $\beta$ & $t$ & $p$ \\
\hline \multicolumn{4}{|l|}{ Driver background characteristics } \\
\hline Gender $($ female $=0 ;$ male $=1)$ & $\mathrm{NE}$ & - & - \\
\hline Highest attained level of education & -.09 & -2.5 & .020 \\
\hline Age (range $17-30$ years) & $\mathrm{NE}$ & - & - \\
\hline Kilometers driven per year & .13 & 3.4 & .001 \\
\hline Years of experience on moped & $\mathrm{NE}$ & - & - \\
\hline \multicolumn{4}{|l|}{ Reported driving behavior } \\
\hline Degree of violating driving behavior & .19 & 5.0 & .000 \\
\hline Reported driving speed (on various roads) & $\mathrm{NE}$ & - & - \\
\hline Adjusted $R^{2}$ & .07 & & \\
\hline
\end{tabular}

Note. $\mathrm{NE}=$ variable not in the equation, after stepwise regression analysis.

* None of the moral reasoning variables in the equation and left out of the table

\section{DISCUSSION}

In this study, we developed assessments to explore the moral reasoning levels of young drivers who participated in the Dutch post-license coaching program, 'Drive Xperience' (DX). Drawing from literature on juvenile crime that shows associations between moral reasoning and delinquent behaviors, we investigated the relationship between moral reasoning, self-reported driving behavior and traffic violations. We hypothesized that if scores on our assessments were associated with violating behaviors, it would be appropriate to incorporate these assessments in the DX-program as a means of eliciting socio-moral reflection. Our first research question explored the levels of moral reasoning that are used by DX-participants. Results showed that young drivers use motives on all moral levels to justify their compliance with traffic rules. There is a large variance within each moral level, meaning that there are individual differences between young drivers. Space competing driving, in which young drivers seek to win a space conflict with other road users, is less frequently found than space allotting driving. Looking at selfserving cognitive distortions, although the majority of young drivers hardly engage in these distortions, there is still a considerable amount of young drivers (around 20 per cent) who do use them. The results for the second research question were as expected. First, to the degree that young drivers report the morally immature motive of preventing fines to comply with traffic 
rules, they drive faster and commit more traffic violations. The number of violations in turn predicted some of the variance in the number of fines, in addition to mileage and gender - where men commit more violations than women. Second, self-serving cognitive distortions of undesirable driving behavior is predictive for driving at higher speeds and space competing driving. Third, the morally mature motive for rule compliance (prevent unsafety or blocking of traffic flow) had an inhibiting effect on driving speed and space competing driving.

Reflecting on the results, it seems that the addition of a moral reasoning component to the postlicense coaching of young drivers could have safety benefits in terms of increasing safe driving behaviors. The level of moral reasoning can be measured consistently and appears to be associated with social driving and engagement in traffic violations. First impressions by driving coaches indicate that the profiles elicit reflection on personal motives both for engaging in speed violations and for avoiding them. One potential area for follow-up research would be to explore the added value of socio-moral reflection to what is already addressed in the young driver coaching program. The ability to empathize with the perspectives and needs of other road users might be an overlooked or underappreciated component of driving competence. The next step will be to develop coaching interventions that elicit socio-moral reflection in order to help young drivers adopt more socially and morally responsible driving behaviors. Outcome evaluations measuring traffic violation and crash data would be a subsequent step.

\section{REFERENCES}

Barriga, A. Q., Morrison, E. M., Liau, A. K., \& Gibbs, J. C. (2001). Moral cognition: Explaining the gender difference in antisocial behavior. Merrill-Palmer Quarterly, 47(4), 532-562.

Beanland, V., Goode, N., Salmon, P.M., Lenné, M.G. (2013). Is there a case for driver training? A review of the efficacy of pre- and post-licence driver training. Safety Science, 51, 127-137.

Gibbs, J. C. (2003). Moral Development and Reality - Beyond the Theories of Kohlberg and Hoffman. London: Sage Publications Ltd

Gibbs, J. C. Barriga, A. Q., \& Potter, G. B. (2001). How I Think (HIT) Questionnaire. Champaign, IL: Research Press.

Gregersen, N.P. \& Bjurulf, P (1996). Young novice drivers: Towards a model of their accident involvement. Accident Analysis and Prevention, 28, 229-241.

Gregg, V. R., Gibbs, J. C., \& Basinger, K. (1994). Patterns of developmental delay in moral judgment by male and female delinquents. Merrill-Palmer Quarterly, 40, 538-553.

Isler, R.B., Starkey, N.J., Sheppard, P. (2011). Effects of higher-order driving skill training on young, inexperienced drivers' on-road driving performance. Accident Analysis Prevention, 43, 1818-1827.

King, K.A., Vidourek, R.A., Love, J., Wegley, S., Alles-White, M., 2008. Teaching adolescents safe driving and passenger behaviors: effectiveness of the You Hold the Key Teen Driving Countermeasure, Journal of Safety Research, 39, 19-24.

Leeman, L.W., Gibbs, J.C., Fuller, D. (1993). Evaluation of a multi-component group treatment program for juvenile delinquents. Aggressive Behaviour, 19(4),281-292

Stams, G. J., Brugman, D., Deković, M., \& van Rosmalen, L. (2006). The moral judgement of juvenile delinquents: A meta-analysis. Journal of Abnormal Child Psychology, 34, 697-713.

Van Stam, M.A., Van der Schuur, W.A., Tserkezis, S., Van Vugt, E.S., Asscher, J.J., \& Gibbs, J.C. (2014). The effectiveness of EQUIP on sociomoral development and recidivism reduction: A meta-analytic study. Children and Youth Services Review, 38, 44-51. 